Eastern Illinois University

The Keep

Masters Theses

Student Theses \& Publications

2001

\title{
The Effects of Positive Peer Reporting on Children's Social Involvement
}

\author{
Kristyn B. Moroz \\ Eastern Illinois University \\ This research is a product of the graduate program in School Psychology at Eastern Illinois University. Find \\ out more about the program.
}

\section{Recommended Citation}

Moroz, Kristyn B., "The Effects of Positive Peer Reporting on Children's Social Involvement" (2001). Masters Theses. 1576.

https://thekeep.eiu.edu/theses/1576

This is brought to you for free and open access by the Student Theses \& Publications at The Keep. It has been accepted for inclusion in Masters Theses

by an authorized administrator of The Keep. For more information, please contact tabruns@eiu.edu. 


\section{THESIS/FIELD EXPERIENCE PAPER \\ REPRODUCTION CERTIFICATE}

TO: Graduate Degree Candidates (who have written formal theses)

SUBJECT: Permission to Reproduce Theses

The University Library is receiving a number of request from other institutions asking permission to reproduce dissertations for inclusion in their library holdings. Although no copyright laws are involved, we feel that professional courtesy demands that permission be obtained from the author before we allow these to be copied.

\section{PLEASE SIGN ONE OF THE FOLLOWING STATEMENTS:}

Booth Library of Eastern Illinois University has my permission to lend my thesis to a reputable college or university for the purpose of copying it for inclusion in that institution's library or research holdings.

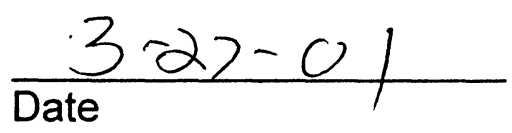

I respectfully request Booth Library of Eastern Illinois University NOT allow my thesis to be reproduced because: 
Running Head: PEER REPORTING

The Effects of Positive Peer Reporting on

Children's Social Involvement

\author{
Kristyn B. Moroz \\ Kevin M. Jones, Ph.D. (Thesis Chairperson) \\ Eastern Illinois University
}


The Effects of Positive Peer Reporting

on Children's Social Involvement

(TITLE)

BY

Kristyn B. Moroz

\section{THESIS}

SUBMITTED IN PARTIAL FULFILLMENT OF THE REQUIREMENTS FOR THE DEGREE OF

Specialist in School Psychology

IN THE GRADUATE SCHOOL, EASTERN ILLINOIS UNIVERSITY CHARLESTON, ILLINOIS

2001

YEAR

I HEREBY RECOMMEND THAT THIS THESIS BE ACCEPTED AS FULFILLING THIS PART OF THE GRADUATE DEGREE CITED ABOVE

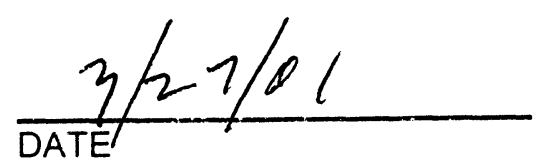

$3 / 2, \%$

DATE 
Table of Contents

$\underline{\text { Page }}$

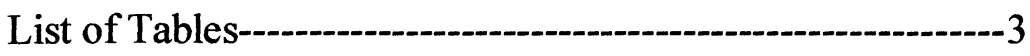

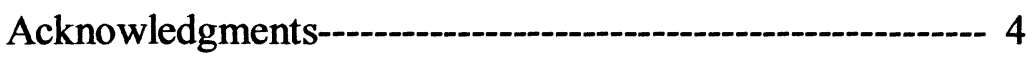

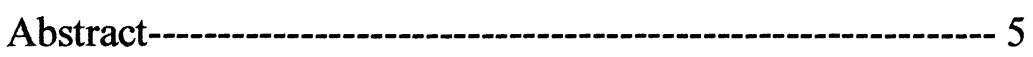

Introduction and Review of the Literature--

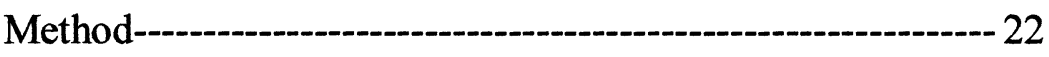

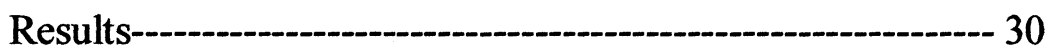

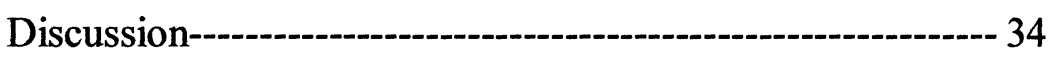

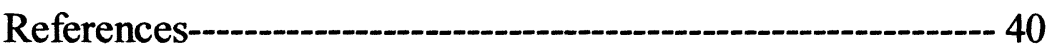

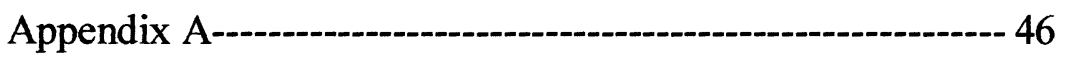

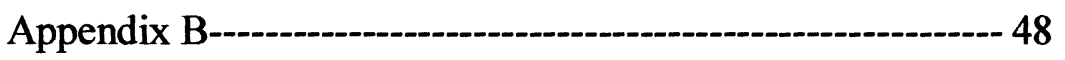

Appendix C-1- 50

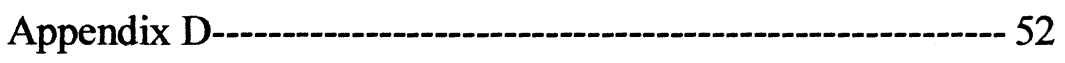

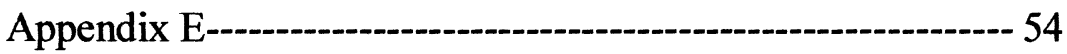

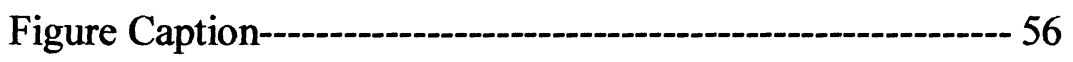


Peer Reporting 3

\section{LIST Of TABLES}

Table

$\underline{\text { Page }}$

1 Mean Levels of Social Involvement Behavior-------------------33 


\section{ACKNOWLEDGMENTS}

I would like to acknowledge a few individuals for their assistance with this project. First, I would like to thank Dr. Kevin Jones, Dr. Gary Canivez, and Dr. Linda Leal for all their assistance and encouragement throughout this project. Special thanks to Dr. Kevin Jones for his patience, time, and support.

I would also like to thank the teachers and principal who volunteered their time and service to participate in this study. I would also like to acknowledge that this project was funded, in part, by a research grant from the Illinois School Psychologists Association.

I would like to thank my family and friends for their encouragement and support throughout this project. 


\begin{abstract}
This investigation examined the effectiveness of positive peer reporting (PPR) on increasing the social involvement behavior and peer acceptance of four socially withdrawn children within a general education setting. PPR is a social skills intervention where children are taught how to publicly praise a target classmate's appropriate behavior. The positive peer reporting procedure was implemented daily by each participant's classroom teacher and its effects were observed during recess using behavioral observations. The results indicated that PPR had no effect on peer status. However, results from the behavioral observations indicated that three of the participants exhibited higher rates of social involvement behavior after the procedure was implemented. Additional findings and implications for future research are also discussed.
\end{abstract}




\section{CHAPTER I}

The Effects of Positive Peer Reporting on Children's Social Involvement

Previous research has indicated that children who display maladjusted behaviors (e.g. aggression and withdrawal) during early childhood are frequently not accepted by peers which in turn, places them at risk for a various negative outcomes later in life including delinquency, substance abuse, premature dropping out of school, and psychopathology (Parker \& Asher, 1987). Although children who experience poor peer relationships are at great risk for developing various maladjustment problems, it should be noted that the consequences for these children vary. Specifically, previous research has suggested that children who experience poor peer relationships make up a heterogeneous group and the extent to which a child displays either aggression, withdrawal, or both is predictive of long term outcomes (Parker \& Asher, 1987; Hymel, Rubin, Rowden \& LeMare, 1990; Harrist, Zaia, Bates, Dodge \& Pettit, 1997). For example, children who display aggressive types of behaviors are at greater risk for the development of externalizing problems (e.g. delinquency) later in life whereas children who are shy/withdrawn tend to develop internalizing difficulties such as depression.

Interestingly, socially withdrawn children are becoming more of a primary interest to educators. Perhaps, the growing interest in this particular population is the result of recent research that has identified several outcomes associated with social withdrawal during childhood. For example, low levels of appropriate social interactions during childhood has been found to be correlated with poor academic performance, early school drop out, low self esteem, and social anxiety 
(Sheridan, Kratochwill \& Elliott, 1990). Furthermore, the ability to initiate and sustain positive peer relationships is considered to be an essential aspect of child development such that children learn appropriate modes of social conduct by interacting with peers. Finally, longitudinal studies have found that children who are withdrawn tend to display increased amounts of internalizing problems as they grow older (Rubin \& Mills, 1988). Clearly, these studies illustrate the influence of early childhood peer interactions on children's social behavior and development. In addition, they justify the need for the development of interventions that focus on increasing social involvement behavior in socially withdrawn children.

A massive aggregation of literature exists supporting the notion that peers are powerful social influences on child development, and more specifically, suggests that peers are powerful social influences on children's behavior (e.g., Patterson \& Anderson, 1964; Strain, 1981; Odom \& Strain, 1984; Sancilio, 1987). For example, Bueler, Patterson and Furness (1966) examined the influence of peer reinforcement on antisocial behavior and suggested that peers have the ability to bring about deviant behaviors in delinquent children. Data were collected on how peers responded to a delinquent classmate's prosocial and antisocial behaviors. The results from the analyses indicated that peers gave higher amounts of social approval to the delinquent classmate when they engaged in antisocial behaviors.

Previous researchers have applied functional assessment and analysis in order to examine specific variables that maintain children's disruptive behavior in regular education settings (Broussard \& Northup, 1995). Functional analysis is a 
procedure that is used to examine the relationship between problem behaviors and related antecedent and consequent events. During this procedure, antecedent and consequent events suspected of contributing to the occurrence of a problem behavior are manipulated in order to determine likely functional relationships.

An example of the utility of functional analysis for determining variables that contribute to a problem behavior was demonstrated by Broussard and Northup (1995). Behavioral observations of three children were conducted following the manipulation of three variables hypothesized to influence each child's classroom misbehavior (e.g. peer attention, teacher attention, and escape from academic demands). The results from the observations indicated that for one student, disruptive behaviors occurred more frequently when followed by peer attention. Based on this finding, it was hypothesized that a motive for this particular student's misbehavior was to access to peer attention. In order to further examine this hypothesis, the authors asked the child to complete academic assignments during two conditions. In the first condition, the child completed the academic assignments in an empty room with only the observers present. Conversely, during the second condition, the child completed the academic assignments in a room with two peers present. Data from the observations and analyses indicated that when peers were absent, the child displayed no disruptive behaviors and completed all of the academic assignments. On the other hand, when peers were present, the frequency of the child's misbehaviors increased and work completion decreased. Based on these findings, the authors suggested that peer attention can play a significant role in maintaining a child's disruptive 
classroom behavior.

Northup, Jones, Broussard, George, Vollmer, and Herring (1995) also explored the powerful effects of peer attention on misbehavior. However, this study used peer and teacher attention in order to manipulate the occurrence of disruptive behavior in three children diagnosed with Attention Deficit Hyperactivity Disorder. During the teacher attention condition, a teacher provided the hyperactive children with attention each time they engaged in an inappropriate behavior. Similarly, during the peer attention condition, peer confederates were instructed to provide attention to the hyperactive children each time the hyperactive children engaged in a disruptive behavior. The results indicated that the hyperactive children displayed more inappropriate behaviors during the contingent peer attention condition than the contingent teacher attention condition. Likewise, in a study conducted by Northup, DiGiovanni, Herring, Fusilier, and Hanchey (1997), contingent peer attention was more influential in provoking the occurrence of disruptive behavior than contingent teacher attention. The results from both of these studies suggest that children's misbehaviors can be maintained by peer attention.

\section{Peer -Mediated Approaches}

Given the potential powerful influence of peer attention on children's behavior, various social skills interventions have been developed that utilize peers as therapeutic agents in order to produce and maintain desirable behaviors in classroom settings (Sancilio, 1987). During Programmed Peer Interaction Interventions, a peer who is approximately the same age as a target child is taught 
how to administer social reinforcement in order to bring about behavior change in the target child. Throughout this type of intervention adults play a minimal role and at most may monitor the procedure (Odom \& Strain, 1984). Previous research has described some of the primary benefits associated with peer mediated interventions and suggested that using children is more cost-effective and provides adults with extra time to engage in more instructional activities (Sancilio, 1987). Furthermore, Sancilio (1987) argued that certain interventions require the use of peers because the therapeutic goals of these interventions require the target child to interact with peers (Sancilio, 1987). In addition, other researchers have suggested that peers are more capable than adults in changing a target child's behavior because as children grow older the peer group becomes more significant and as a result, children are more likely to respond to their peers than adults (Damon, 1984; Strain, 1982). Similarly, Field (1981) indicated that peers are more effective in bringing about behavioral changes in children because the interactions and relationships between children and peers are equal and less intimidating in nature than child-adult interactions.

Numerous studies have been conducted that utilized peers in order to modify children's inappropriate behaviors in a variety of settings. One of the first peer-mediated studies used peers as social reinforcers in order to prompt simple motor behaviors in second, third, and fourth grade children (Patterson \& Anderson, 1964). During this particular study, each target child received verbal praise from either a preferred or nonpreferred classmate each time they engaged in a certain motor behavior. The results indicated that peer reinforcement was 
effective in changing the target child's behavior. Furthermore, the target children demonstrated even greater changes in motor behavior when the reinforcement was provided by a preferred classmate. Based on these findings, the authors suggested that using peers as social agents may be an effective method for prompting specific social responses in children.

Solomon and Wahler (1973) further examined the effects of using peer reinforcement in order to modify children's inappropriate behaviors. Specifically, sixth grade children were instructed to provide a disruptive classmate with social attention (e.g. verbal praise or physical contact) each time they observed him or her engaging in appropriate behavior. Behavioral observations were conducted on the frequency of appropriate and inappropriate behaviors displayed by the disruptive classmates before and after treatment. The results from the observations indicated that the disruptive classmates engaged in fewer disruptive behaviors and more appropriate behaviors when provided with contingent social attention. Based on these findings, Solomon and Wahler (1973) suggested that disruptive classroom behaviors could be modified into more desirable behaviors by manipulating peer attention.

Similarly, previous studies have used peer pressure in an attempt to reduce disruptive classroom behavior (Bellafiore \& Salend, 1983; Sandler, Arnold, Gable \& Strain, 1987). During a peer-confrontation intervention, peers challenge disruptive classmates to be attentive of their misbehavior and its effects on others. Peers also give suggestions to the disruptive classmate on ways that they can improve their disruptive behavior. Previous studies using this procedure revealed 
that it was effective on reducing inappropriate behaviors and increasing positive behaviors in disruptive children. Furthermore, previous research has suggested that positive peer pressure is an effective and practical method for teaching school-aged children appropriate ways of dealing with peer related problem situations (Bellafiore \& Salend, 1983; Sandler, Arnold, Gable \& Strain, 1987).

Other studies that have used peers as change agents suggest that peers can modify inappropriate behaviors exhibited by their classmates through peer monitoring. During a peer monitoring intervention, children are taught how to observe and keep track of a disruptive peer's appropriate and inappropriate behaviors. In addition, children are instructed to prompt the disruptive peer to engage in appropriate behaviors and are trained on how to publicly reinforce the peer when they observe him or her displaying an appropriate behavior. Finally, children are instructed to withhold points and reinforcement if they observe the disruptive peer engaging in an inappropriate behavior. The effectiveness of this procedure was examined in a study conducted by Carden-Smith and Fowler (1984). Specifically, kindergarten children were taught how to monitor appropriate and inappropriate behaviors in disruptive peers. In addition, the children were trained on how to award points to the peers for appropriate behaviors and withhold points for inappropriate behaviors. The results indicated that the peer monitoring procedure was effective on reducing disruptive behaviors and increasing participation behaviors in the disruptive children. In addition, it was found that the children who served as peer monitors were capable of implementing the peer monitoring procedure, were accurate in identifying 
appropriate behaviors and were capable of awarding points to the target peers. However, it was also found that the children who served as peer monitors were not accurate in withholding points from the disruptive peers. Some possible explanations for this finding were that the peer monitors lacked the accuracy and skill for identifying misbehaviors, had different perceptions of misbehavior, or their classmates provided them with reinforcement when they awarded points. Despite this limitation, Carden- Smith and Fowler (1984) argued that peer monitoring is an effective intervention for reducing negative behaviors and increasing positive behaviors in disruptive children.

A similar study conducted by Dougherty, Fowler, and Paine (1985) employed the peer-monitoring procedure in order to improve the negative behaviors of a mildly mentally retarded child. The procedure used during this study was adopted from an earlier intervention program entitled RECESS: Reprogramming Environmental Contingencies for Effective Social Skills (Walker, Street, Garrett, Crossen, Hops, and Greenwood, 1978). The specific components adopted from this program included: individual social skills training, class-wide social skills training, a point system, and a daily and weekly reward system. In addition to these conditions, a peer-monitor training program was applied. The results of this study revealed that the participant's rate of negative interactions decreased when monitored by either an adult or peer and that these reductions were maintained throughout the entire morning. It was also found that the participant exhibited even fewer negative interactions when they served as a peer monitor for another classmate. Data were also collected on the participant's 
rate of positive interactions and rule infractions before and after the peer monitoring procedure. The results indicated that during the peer monitoring intervention, the participant engaged in more positive interactions, and fewer rule infractions. Furthermore, the participant maintained these improvements on days in which they were not a peer monitor. Based on these findings, the authors suggested that peer monitoring is not only an effective procedure for increasing positive behaviors in children who are monitored, but it also has the ability to enhance prosocial behaviors in children who serve as peer monitors.

\section{Positive Peer Reporting}

Guided by previous literature that supports the benefits of using peers as change agents, researchers have also investigated the effects of peers publicly reporting positive aspects of a disruptive classmate's behavior in order to modify their deviant behaviors as well as social acceptance (Ervin, Johnston, \& Friman, 1998; Ervin, Miller \&, Friman, 1996; Grieger, Kauffman, \& Grieger, 1976; Jones, Young, \& Friman, 2000). Positive Peer Reporting (PPR) is a social skills intervention that involves teaching peers how to publicly acknowledge a target classmate's appropriate behaviors.

Current studies that have utilized the positive peer reporting procedure indicate that implementing this procedure is a simple process and requires the following steps. First, all children in a classroom are taught the necessary skills for praising a peer appropriately. Specifically, these skills include looking at the target classmate, smiling, reporting something positive about the target classmate's behavior, and finally, praising the classmate for engaging in the 
behavior. Next, the teacher nominates a target classmate who will be exposed to the positive peer reporting procedure. Finally, at one point during the school day the teacher will ask each student in the class to make a positive comment about any appropriate behavior that they observed the target classmate engaging in using the four essential skills previously taught.

One of the first studies to utilize the positive peer reporting procedure examined its effects on improving the social interactions and peer status of a socially rejected aggressive girl in a residential setting (Ervin, Miller, \& Friman, 1996). At the end of the day students were instructed by the teacher to make positive comments about the socially rejected girl's appropriate behavior and were rewarded points for direct, genuine, and specific comments. Observations were conducted on the socially rejected girl's interactions throughout the study. Additionally, sociometric ratings were collected before and after the intervention. The results indicated that the positive peer reporting procedure was effective in reducing the frequency of negative social interactions and increasing the frequency of positive interactions exhibited by the socially rejected student. In addition, the socially rejected student also experienced an increase in peer status after being exposed to the positive peer reporting procedure. Based on these findings, the authors suggested that peers are capable of improving the social interactions of socially rejected classmates by publicly acknowledging their positive behaviors. Additional research has found that the positive peer reporting procedure produced similar improvements in socially rejected males as well (Bowers, McGuinnes, Ervin, \& Friman, 1999). 
Additional research has extended the positive peer reporting procedure to general education settings. Ervin, Johnston, and Friman (1998) examined the effects of this procedure on improving the social interactions and acceptance of a socially rejected first grade girl. The procedures that were utilized during this study were identical to the ones used in previous positive peer reporting studies. However, in order to make the positive peer reporting procedure more applicable to a general education setting, tangible reinforcers were given to classmates for appropriate comments instead of points. Observational data were obtained daily regarding the quality of social interactions that the participant engaged in. Results from these observations indicated that the participant engaged in fewer negative interactions and greater positive interactions during the positive peer reporting procedure. Likewise, results from teacher satisfaction ratings indicated a high level of treatment acceptability for the procedure. Furthermore, it was also found that the participant experienced a slight increase in peer status after the intervention. The authors concluded that future research should replicate the positive peer reporting procedure in a general education setting in order further examine its effects on children's peer status. Based on these findings, the authors concluded that the positive peer reporting procedure is an effective procedure for improving classroom misbehavior. In addition, the results from the teacher satisfaction ratings further demonstrated that this procedure is highly regarded by teachers.

Recent studies have also explored specific behaviors that change in children as a result of being exposed to the positive peer reporting procedure 
(Jones, Young, \& Friman, 2000). Specifically, Jones et al. (2000) examined the effects of positive peer reporting on increasing the cooperative behaviors and social acceptance of three socially rejected delinquent adolescents. Observations were conducted on the frequency of cooperative statements that each participant made toward a peer. The results from these observations indicated that the three children directed more cooperative statements towards peers and experienced an increase in peer status after the positive peer reporting procedure was implemented. Additionally, results from teacher ratings indicated a high level of treatment acceptability for the positive peer reporting procedure.

The findings from the previously described studies provide strong evidence to support the efficacy of the positive peer reporting procedure for decreasing misbehavior and increasing appropriate behavior in socially rejected aggressive children. Furthermore, children exposed to the procedure frequently experienced an increase in peer status. Finally, these studies demonstrated that the positive peer reporting procedure can be implemented in both residential and general education settings.

\section{Limitations of Existing Literature}

Although previous positive peer reporting studies have demonstrated that this procedure is capable of producing significant changes in children's behavior, there are some limitations regarding their generalizability. First, previous positive peer reporting studies have primarily focused on reducing externalizing (e.g. aggression) behaviors in socially rejected youth in order to improve their social interactions (Jones, Young, \& Friman, 2000). Since children with social 
difficulties exhibit a broad range of deviant behaviors (e.g. aggression, withdrawal), it is possible that the positive peer reporting procedure would produce different changes in children who display other types of deviant behaviors (e.g. social withdrawal). This is a significant limitation because previous research has indicated that socially rejected children who display deviant behaviors make up a heterogeneous group. Furthermore, different subgroups of socially rejected children can be characterized according to the extent they exhibit a specific maladjusted behavior such as aggression or withdrawal (Hymel, Bowker, \& Woody, 1993; Harrist, Zaia, Bates, Dodge, \& Pettit 1997). Harrist, et al. (1997) expanded on this notion regarding the heterogeneity of socially rejected children and suggested that children who are socially withdrawn can be divided into four distinct subgroups: passive-anxious, unsociable, active-isolate, or sad/depressed. Specifically, Harrist et al. (1997) described passive-anxious children as children who have a desire to play with their peers, but are inhibited because of their fear of social situations. In contrast, active-isolates were described as children who are socially unskilled (e.g. immature or aggressive) and have a desire to interact with their peers. However, because these children lack the necessary social skills for engaging in appropriate social interactions, peers often reject them. Unsociable children were characterized as children who have appropriate social skills, but prefer to play alone. Finally, Harrist et. al. (1997) suggested that sad/depressed children resemble children who are diagnosed with depression. In this particular study, Harris et al. (1997) found that children within each of these subgroups differed in terms of popularity, rejection, and social- 
information processing and suggested that children who display a particular subtype of social withdrawal (e.g. unsociable, passive-anxious) experience fewer problems later in life than children who display other subtypes.

Based upon these implications, the present study investigated the effects of the positive peer reporting procedure in children who were socially withdrawn. Since previous research has indicated that the positive peer reporting is an effective procedure for improving the social interactions of socially rejected aggressive children, this study was concerned with determining whether this procedure would produce similar improvements in socially withdrawn children.

One reliable method for identifying children who are socially isolated is the use of norm referenced instruments. In particular, a popular norm referenced instrument that has demonstrated accuracy in identifying social withdrawal in children is The Adjustment Scales for Children and Adolescents (McDermott, Marston, \& Stott, 1993). The Adjustment Scaled for Children and Adolescents (ASCA) is an objective behavior assessment instrument that is designed to assess multisituational expressions of behavior pathology in children between the ages of 5 and 17 (McDermott, 1994). It is administered to a youth's classroom teacher and takes approximately 20 minutes to complete. The ASCA contains 96 items that are divided into six core syndromes of psychopathology (Attention Deficit Disorder, Solitary Aggressive Provocative, Solitary Aggressive Impulsive, Oppositional Defiant, Diffident, and Avoidant) and two supplementary syndromes of behavior pathology (Delinquent and Lethargic). The scores on the individual scales are converted into normalized $\underline{T}$ scores to determine whether an individual 
is maladjusted or at risk for developing a social or emotional disturbance. One scale on the ASCA that specifically addressees withdrawn types of behaviors is the Diffident scale. The Diffident scale consists of 13 items that distinguish shy and timid behavior. Previous research has indicated that this instrument possesses excellent psychometric properties and the norms are nationally representative of children between the ages of 5 and 17 (McDermott, 1994). The ASCA also has high internal consistency and subtest specificity among its scales. In particular, the Diffident scale has an internal consistency of .81 and its subtest specificity is .58. Psychometric properties of this nature indicate that the Diffident scale specifically measures withdrawn types of behaviors, and that a teacher's ratings for each of the items on this scale are accurate and not influenced by error.

Previous positive peer reporting studies have also only studied the effectiveness of this procedure primarily in structured (e.g. classroom) settings. Currently, no studies have examined the effectiveness of the positive peer reporting in unstructured settings (e.g. recess). Based upon this limitation, recess was selected as the primary setting. In addition to examining the effects of this procedure during recess, we were interested in examining it's influence on the participant's social involvement behavior, particularly since socially withdrawn children often play alone and rarely take initiative to interact with peers (Harrist, Zaia, Bates, Dodge, \& Pettit, 1997).

\section{Purpose of the Study}

The current investigation examined the effectiveness of positive peer reporting on increasing two forms of social involvement behavior in socially 
withdrawn children. Daily observations were conducted on the frequency of the participant's social engagement and participation behaviors during recess. It should be noted that the effectiveness of the positive peer reporting procedure was investigated on children enrolled in first through third grade. This particular age group was selected for two reasons. First, previous research has indicated that children in early elementary school do not have a clear understanding of withdrawn behavior and therefore, do not label it as deviant (Younger, Schwartzman, \& Ledingham, 1986). Second, previous research has suggested that children in early elementary school perceive peers who exhibit withdrawal differently than peers who display other maladaptive behaviors like aggression (Graham \& Hoehn, 1995). For example, Graham \& Hoehn (1995) suggested that children at this age level are much more tolerant of peers who are withdrawn, do not perceive them as being responsible for their behavior, and evoke more sympathy towards them. Based upon these findings, it was expected that peers in the early elementary classrooms who participated in the current study would be more willing to make positive statements about a classmate who exhibited withdrawn behaviors. Finally, this study investigated the effects of the positive peer reporting procedure on the sociometric status of the children selected to participate in our study. Since previous studies have found that positive peer reporting is an effective procedure for increasing peer status in socially rejected aggressive children, it was hypothesized that it would also increase the peer status of our socially withdrawn participants. 


\section{CHAPTER II}

\section{Method}

\section{Participants and Setting}

Four students enrolled in one elementary school located in the Midwest were selected to participate. After obtaining approval from the local school district, the primary investigator asked teachers for their assistance in the study. Four teachers were asked to identify one child in their classroom who exhibited withdrawn, shy, timid, and anxious behaviors. The teachers then distributed Parental Consent Letters to the selected students, and only those with parental consent were allowed to participate (see Appendix A). In order to screen participants for withdrawal, The Adjustment Scales for Children and Adolescents (ASCA) was completed by each participant's teacher. Participants who received normalized $\underline{T}$ scores of 60 or greater on the Diffident scale were considered withdrawn.

Katie. Katie was an 8 year old female in third grade. According to Katie's teacher, Katie frequently played alone during recess and free time and never initiated social interactions with peers. Teacher ratings on the ASCA were in agreement with these comments. On the ASCA, Katie's teacher indicated that Katie frequently needed encouragement to participate in team games, did not stand up for herself, and would let other students push ahead of her in line. In addition, Katie received a $\underline{T}$ score of 61 on the Diffident scale, which was in the 84th percentile and in the at-risk range for the development of an emotional or social disturbance. 
Carrie. Carrie was a 7 year old female enrolled in first grade. Reports from Carrie's teacher indicated that Carrie got along with other children in the class. However, Carrie's teacher also reported that Carrie was shy, rarely took initiative to interact with other children, and frequently played alone during recess. Ratings on the ASCA that addressed Carrie's social behaviors were commensurate with these comments. On the ASCA, Carrie's teacher indicated that Carrie needed encouragement to participate in team games, did not stand up for herself, and was never in trouble because she was so timid. On the Diffident scale, Carrie received a $\underline{T}$ score of 74 , which was in the 99 th percentile and in the maladjusted range.

Bob. Bob was a 7 year old male in first grade. According to Bob's teacher, Bob frequently played alone during recess and did not have any friends in the class. Bob's teacher also reported that on occasions where Bob tried to interact with peers, he did so in an intrusive manner. Interestingly, these reports were not in agreement with the ratings on the ASCA. Specifically, on the ASCA, Bob's teacher indicated that he had two or more companions with whom he got along, he engaged in sensible activities, and respected others property. Furthermore, Bob received a $\underline{T}$ score of 40 on the Diffident scale, which was in 16th percentile and in the adjusted range.

Sarah. Sarah was a 10 year old female in third grade. Sarah's teacher expressed concern about Sarah's poor social skills and lack of friends. Teacher ratings on the ASCA also indicated that Sara displayed poor social skills and had few friends. Specifically, on the ASCA, Sarah's teacher indicated that Sarah was 
frequently disruptive, quarreled with other students, and had few friends. In addition, Sarah's $\underline{T}$ score of 67 on the Diffident scale was in the 93rd percentile and in the maladjusted range.

In sum, the results from teacher reports and teacher ratings on the ASCA indicated that Katie, Carrie, and Sarah received standard $\underline{T}$ scores greater than 60 on the Diffident scale. According to McDermott (1994), a child who receives a standard score of 60 or above on the Diffident scale is considered to be displaying higher amounts of shy, timid, and withdrawn behaviors than other children their age. Based upon the results from this instrument along with the behavioral observations that were collected during baseline, the investigator was confident that the participants exhibited high amounts of withdrawn behaviors before the positive peer reporting procedure was implemented.

\section{$\underline{\text { Response Measurements }}$}

Social Withdrawal Observation Form (SWOF). Each participant's social involvement behavior was directly observed daily during 30 minute recess periods using the SWOF (Lewis \& Suagi, 1993). Specifically, the occurrence or nonoccurrence of five target behaviors were recorded during each continuous 10 s. interval (see Appendix B). The operational definitions for each behavioral category were adopted from the Systematic Screening for Behavioral Disorders Scale: Peer Social Behavior Observation Training Manual (Walker, Todis, Block, \& Severson, 1988): (a) "Social Engagement"- the child is interacting with peer(s) verbally or non-verbally in a positive manner, such as talking, holding hands while walking, or playing together on a piece of playground equipment, 
(b) "Participation"- the child is involved in a game with structure or rules, (c) "Parallel Play"- the child is engaged in similar activity as peer(s) but not directly interacting (verbally or non-verbally), such as swinging next to a peer but not initiating or responding to social interactive cues such as talking, smiles, or eye-contact, (d) "Alone"- the child is not within five feet of peer(s) or adults, and (e) "No Codeable Response"- indicating that the child is interacting with adults, out of sight of observer, or engaging in a behavior that does not fit into one of the categories (see Appendix C).

Intervals were cued through an audiotape that issued 10s. prompts. The percentage of intervals containing either "Social Engagement" or "Participation" were used to obtain a total percentage of social involvement behavior for each participant (Walker, Todis, Block, \& Severson, 1988).

Two undergraduate psychology students served as the primary observers throughout the study. The observers were trained for approximately two weeks prior to data collection in order to ensure that they had a clear understanding on how to code and record each behavioral definition. The primary investigator served as the secondary observer for $31 \%$ of the observations during data collection in order to establish interobserver agreement (IOA). IOA was calculated by dividing the number of agreements on the occurrence or nonoccurrence of social involvement (social engagement or participation) within each 10s. interval by the total number of observed intervals, and multiplying that figure by 100 (Hartmann, 1977). IOA averaged 92\% (range, $75 \%$ to $100 \%$ ) across all observations. 
Sociometric Ratings. In order to assess the effects of the positive peer reporting procedure on the peer status for each of the participants, each student in the class was asked to complete an anonymous sociometric rating (Oden, 1980). Specifically, students were asked to write the names of five classmates with whom they most frequently played with during free time (see Appendix D). The social status of each participant was calculated by adding the number of peers who specifically mentioned the participant's name.

\section{Experimental Conditions}

Baseline. During baseline, each of the participant's social involvement behavior was observed and recorded under natural conditions during afternoon recess. Interactions between target students and others were handled in a manner that was consistent with the teacher's normal routine.

Positive peer reporting. During treatment conditions, daily observations of each participant's social involvement behavior continued to be observed and recorded during afternoon recess. The positive peer reporting procedure was implemented following afternoon recess or shortly thereafter. The positive peer reporting procedure used in this study was used in a similar study conducted by Jones, Young, and Friman (2000).

Before the first day of the positive peer reporting procedure, the teacher announced to the class that they were going to work on social skills:

"For the next few weeks, our class will be working on social skills. One student each week will be the "star" of the class. Everyone in the class will have a chance to praise the star's good behavior. How do we praise good behavior?" The four steps are: 
(1) Look at the person.

(2) Smile.

(3) Report something positive the person did or said during the day.

(4) Say something like "good job" or "way to go."

Students were given examples and nonexamples of appropriate praise statements. Students were also given opportunities to provide their own examples of appropriate praise statements and were encouraged to ask questions. On the next day and each subsequent day for approximately 5-7 minutes, the teacher provided the students with an opportunity to make praise statements. When observations indicated that the participant displayed a relatively consistent pattern of social involvement behavior, the treatment was terminated and another child in the participant's class was exposed to the procedure. Due to concerns regarding the publicity aspect of this procedure, all of the teachers who participated decided to give all their students an opportunity to be exposed to the positive peer reporting procedure after it was terminated for the target child.

\section{Design}

A multiple baseline across subjects design with a reversal was used in order to evaluate the effectiveness of the positive peer reporting procedure. Specifically, behavioral observations were conducted on the frequency of social involvement behavior exhibited by each participant during recess. The Social Withdrawal Observation Form represented the primary dependent measure and was evaluated across baseline, treatment, and reversal conditions. Baseline data 
collection began at the same time for each participant. Katie was the first participant to be exposed to the positive peer reporting procedure, while baseline continued for Carrie, Bob, and Sarah. After the initial effects of the positive peer reporting procedure for Katie were established, the treatment phase began for Carrie, followed by Bob, and finally, Sarah. Each of the participants were exposed to the procedure for eight days. However, the dates in which the procedure began for each of the participants were different. Specifically, the starting dates for each participant varied across a two week period. The reversal phase for each participant was initiated after stable treatment effects were obtained. Similar to the treatment phase, the dates for when the procedure was terminated varied among each of the participants. The same method was consistent for each of the participants which allowed for staggering the baseline, treatment, and reversal phases in terms of length and calendar days. By using repeated measures, it was possible to rule out various threats to the internal validity of this study which included testing effects, regression to the mean, instrumentation, and maturation. Similarly, incorporating a reversal controlled for history effects.

\section{Procedural Integrity}

A checklist was completed each day by the classroom teacher in order to ensure that the positive peer reporting procedure was implemented in a consistent manner (see Appendix E). The checklist included four steps that were necessary for the teacher to correctly implement the procedure. Teachers placed a check next to each step on the days that they implemented the procedure for the 
participants. Treatment integrity was defined as the total number checks marked on the checklist. Treatment integrity was $100 \%$ indicating that all teachers reported implementing every step during each day of the procedure. In addition, results from informal observations indicated that the teachers were implementing the procedure in a consistent manner.

\section{$\underline{\text { Procedures }}$}

First, Human Subjects approval was granted by the Department of Psychology Thesis Committee at Eastern Illinois University. Second, permission from a local school district was obtained and interested teachers were provided with information about the treatment program. A treatment evaluation of the positive peer reporting procedure began after receiving parental consent. The Adjustment Scales for Children (ASCA) and sociometric ratings were obtained before baseline data were collected. Data were collected four to five times a week during baseline, treatment, and reversal phases. A reversal phase was initiated for each participant when the procedure was terminated for that participant and implemented with another peer in the class. After the effects of the positive peer reporting procedure were clear, sociometric ratings were collected again. Finally, follow-up data were collected on each participant approximately four weeks after the procedure was terminated. 


\section{CHAPTER III}

\section{Results}

\section{Behavioral Observations.}

Figure 1 displays the percentage of intervals during which each participant exhibited social involvement behavior across baseline, treatment, reversal, and follow-up conditions.

Katie. During baseline, Katie's mean level of social involvement behavior was $8 \%$ (range, $0 \%$ to $37 \%$ ). After the positive peer reporting procedure was introduced, Katie's mean level of social involvement behavior increased to $36 \%$ (range, $0 \%$ to $97 \%$ ). During the reversal phase, Katie's mean level of social involvement behavior further increased to $81 \%$ (range, $65 \%$ to $100 \%$ ). In terms of sociometric status, Katie's pre-test sociometric score was a 2 indicating that two of her peers nominated her as a preferred playmate. At post-test, Katie' sociometric score was a 1 indicating that she experienced a slight decrease in peer status after the procedure.

Carrie. Carrie also displayed an increase in social involvement behavior during the positive peer reporting procedure. During baseline, Carrie's level of social involvement behavior ranged from $45 \%$ to $65 \%(\underline{\mathrm{M}}=53 \%)$. During the positive peer reporting procedure, Carrie's mean level of social involvement behavior increased to $82 \%$ and ranged from $65 \%$ to $100 \%$. After the procedure was terminated, Carrie's mean level of social involvement behavior decreased to $46 \%$ (range, $33 \%$ to $60 \%$ ). Carrie did not experience any change in sociometric 
status. Specifically, two of Carrie's classmates nominated her as a preferred playmate at both pretest and post-test.

Bob. Despite not experiencing a significant increase in social involvement behavior, Bob exhibited a unique response to the positive peer procedure. During baseline, Bob's level of social involvement behavior was quite variable and ranged from $33 \%$ to $95 \%,(\underline{M}=69 \%)$. After the positive peer reporting procedure was introduced, Bob's mean level of social involvement behavior decreased to $68 \%$, but there was less variability in his social involvement behavior (range, $50 \%$ to $97 \%$ ). During reversal, Bob's level of social involvement behavior ranged from $43 \%$ to $73 \%(\underline{M}=56 \%)$. In terms of peer status, Bob's sociometric score decreased from a two at pre-test to a one at post-test indicating that he experienced a slight decrease in peer status after being exposed to the positive peer reporting procedure.

$\underline{\text { Sarah. }}$ During baseline, Sarah's mean level of social involvement behavior was $26 \%$ (range, $7 \%$ to $65 \%$ ). During the positive peer reporting procedure, Sarah's mean level of social involvement behavior increased to $55 \%$ and ranged from $5 \%$ to $88 \%$. During the reversal phase, Sarah's mean level of social involvement behavior dropped to $31 \%$ (range, $5 \%$ to $47 \%$ ). In terms of Sarah's peer status, none of the students in Sarah's class selected her as a preferred playmate during the pre-test and post-test.

In addition to collecting data during the baseline, treatment, and reversal phases, two extra observations were made on each participant four weeks after the positive peer reporting procedure was terminated. Table 1 displays the mean 
levels of social involvement behavior for each participant across baseline, treatment, reversal, and follow-up phases. Furthermore, Table 1 displays the effect sizes for each participant between baseline and treatment in order to determine whether each participant exhibited a significant difference in social involvement behavior after the positive peer reporting procedure was implemented. 
Peer Reporting 33

Table 1

Mean Levels of Social Involvement Behavior

Participant Baseline Treatment Reversal Follow-up Effect Size

$\begin{array}{lccccc}\text { Katie } & 8 \% & 36 \% & 81 \% & 49 \% & 1.92 \\ \text { Carrie } & 53 \% & 82 \% & 46 \% & 56 \% & 3.72 \\ \text { Bob } & 69 \% & 68 \% & 56 \% & 48 \% & .07 \\ \text { Sarah } & 26 \% & 55 \% & 31 \% & 44 \% & 1.78\end{array}$




\section{CHAPTER IV}

\section{Discussion}

These findings provide empirical support regarding the efficacy of the positive peer reporting procedure in improving children's social involvement behavior during recess. Specifically, these results demonstrated that three socially withdrawn children interacted more frequently with peers during recess after being exposed to the positive peer reporting procedure. This is a significant finding, particularly since previous studies have not investigated the effectiveness of this procedure in socially withdrawn children. Based on this finding, we can further warrant using this procedure to improve various maladaptive behaviors in children (e.g. aggressive, withdrawn).

One important finding from this study was that the positive peer reporting procedure produced changes in a playground setting. This is a significant contribution to the existing literature since the effects of this procedure have only been examined in targeted classroom settings. It was found that individuals can implement the positive peer reporting procedure in one setting (e.g. classroom) and observe and measure its effects in another (e.g. recess). This is a strong advancement to the current literature because a majority of social skills treatments implement and measure effects in analog settings and as a result, neglect to examine whether individuals display their improvements in outside settings. Future research should examine variables that influence generalization (e.g. grade level).

Also, the present findings provided further empirical support for the utility 
of this procedure in a general education setting. This study was the second study to successfully implement the positive peer reporting procedure in a general education setting whereas a majority of previous positive peer reporting studies have implemented this procedure in residential treatment settings. The results from the current investigation along with findings from previous research indicate that the positive peer reporting procedure can be used in both residential and general education settings.

\section{Limitations of the Study}

The present study possesses some limitations, which provide implications for future research. First, although the teachers in our study reported high integrity for implementing the procedure, no systematic reliability checks were conducted in order to determine whether the teachers were implementing the positive peer reporting procedure in a correct and consistent manner. Previous research has questioned the reliability of relying solely on teacher self-report for measuring treatment integrity (Wickstrom, Jones, Lafleur, \& Witt, 1996). Since teacher's self reports were used to measure treatment integrity in the present study, it is possible that the procedure was not implemented correctly or consistently. This shortcoming may serve as one possible explanation for the variability that occurred in some of the participant's social involvement behavior during treatment. Future studies should include systematic reliability checks to ensure that teachers are implementing the procedure correctly and consistently.

A second shortcoming of the present investigation was that Katie did not display a decrease in social involvement behavior after the procedure was 
terminated. This unique effect was not observed in the other participants nor has it been revealed in the previous literature. Although we were pleased to see continued escalation in Katie's social involvement, the lack of reversal makes the effects of the positive peer reporting procedure more difficult to interpret. Perhaps these changes were due to the procedure, but there is a chance they may have been the result of a nonexperimental variable as well (e.g. history).

Finally, none of the participants in the present study experienced an increase in peer status after being exposed to the procedure. This finding is inconsistent with previous positive peer reporting studies which have found that the peer status of individuals exposed to the procedure usually increased or stayed the same. However, most of these studies were implemented in residential settings, and interestingly, results from the one previous study conducted in a general education setting indicated that the participant experienced only a slight increase in peer status. It is possible that increases in peer status take longer to develop in general education settings. For example, general education classrooms contain more students than residential settings and therefore, friendships may take longer to develop. Future studies should replicate the positive peer reporting procedure in general education settings in order to further determine the effectiveness of this procedure on peer status.

\section{Future Directions}

The present investigation measured the effectiveness of the positive peer reporting procedure on the four targeted participants, yet there may be additional outcomes of interest to future investigators. For example, it is well established 
that peer-mediated reinforcement directed toward a target child may lead to an increase in appropriate behaviors in students who are not receiving reinforcement (Kazdin, 1994). This particular phenomenon is commonly referred to as vicarious conditioning and it is based on the idea that reinforcing one child's behavior in the presence of others can sometimes serve as a prompt for the other children to engage in a similar behavior. Previous research has utilized vicarious conditioning in order to reduce various types of misbehaviors (e.g. noncompliance) as well as to increase positive behaviors in children and adolescents (e.g. social interactions). Based on this notion, it is possible that children in our study who were not directly exposed to the positive peer reporting procedure also demonstrated increased rates of social involvement behavior due to observing one of their peers being praised for interacting with peers. This may explain the high percentage of social involvement behavior that was exhibited by Katie after the procedure was terminated.

Future research should investigate additional outcomes associated with the positive peer reporting procedure. For example, it is unclear to what extent the positive peer reporting procedure influences the social milieu of an entire classroom. One of the teachers in our study indicated that the children in her classroom behaved more positively towards one another during the procedure and that children made positive comments towards one another outside the classroom (e.g. lunch room). In addition to examining the effects of positive peer reporting on children not directly exposed to the procedure, future research should determine whether this procedure influences the behaviors and attitudes of 
teachers. For example, teachers may have responded more positively towards their students during the procedure, although this implication would not serve as an explanation for the present results given that changes were observed during recess.

Another direction for future research is to determine whether the positive peer reporting procedure would improve other types of recess behaviors since social involvement was the only behavior targeted in the present study. For example, future research could examine the effectiveness of the positive peer reporting procedure on reducing inappropriate recess behaviors (e.g. aggression). Previous positive peer reporting studies have already found that this procedure is capable of reducing aggressive behavior in children within a classroom setting (Bowers, McGinnes, Ervin, \& Friman, 1999; Ervin, Johnston, \& Friman, 1998; Ervin, Miller \&, Friman, 1996). It would be interesting to see if the same results would occur during recess.

It should also be noted that the present study was the first to assess the extent of social withdrawal in children using a norm referenced instrument before exposing them to the positive peer reporting procedure. Furthermore, previous research has verified that The Adjustment Scales for Children (ASCA) is a reliable instrument for distinguishing two different forms of withdrawal. The Diffident scale consists of items that identify shy and timid behavior. In contrast, the Avoidant scale distinguishes unusually withdrawn, aloof, and uncommunicative. The present study only examined the Diffident scale in order to determine the extent of each participant's withdrawn behavior. It would be 
interesting to determine the effects of the positive peer reporting procedure on children who display behaviors that are characteristic of items that make up the Avoidant scale. As mentioned earlier, withdrawal is a multifaceted construct and the reasons for children's withdrawn behavior are complex. Future positive peer reporting studies should utilize norm referenced instruments in order to adequately determine the extent of and reasons for children's social problems prior to exposing them to the procedure. In turn, through adequate assessment, perhaps we can determine the types of children who would most benefit from this procedure.

Finally, since our findings indicated that the positive peer reporting procedure can be successfully implemented and measured in different settings, future research should investigate whether children would display improvements over time. Previous research has indicated that oftentimes children who are exposed to a social skills intervention do not maintain their newly acquired skills. Currently, there is a great demand for social skills interventions where children maintain long term changes in their behavior. Perhaps alone or in combination with another social skills intervention, children exposed to the positive peer reporting procedure would demonstrate the ability to maintain their newly acquired skills long after the procedure was terminated. 


\section{References}

Bellafiore, L. A., \& Salend, S. J. (1983). Modifying inappropriate behavior through a peer-confrontation system. Behavior Disorders, 8, 274-279.

Bowers, F. E., McGinnis, C., Ervin., R. A., \& Friman, P. C. (1999). Merging research and practice: The example of positive peer reporting applied to social rejection. Education and Treatment of Children, 22, 218-226.

Broussard, C. D. \& Northup, J. (1995). An approach to functional assessment and analysis of disruptive behavior in regular education classrooms. School Psychology Quarterly, 10, 151-164.

Bueler, R. E., Patterson, G. R., \& Furness, R. M.(1966). The reinforcement of behavior in institutional settings. Behavior Research and Therapy, 4, 157-167.

Carden-Smith, L. K., \& Fowler, S. A. (1984). Positive peer pressure: The effects of peer monitoring on children's disruptive behavior. Journal of Applied Behavior Analysis, 17, 213-227.

Damon, W. (1984). Peer education: The untapped potential. Journal of Applied Developmental Psychology, 5, 331-339.

Dougherty, B. S., Fowler, S. A., \& Paine, S. C. (1985). The use of peer monitors to reduce negative interaction during recess. Journal of Applied Behavior Analysis, 18, 141-153. 
Ervin, R. A., Johnston, E. S., \& Friman, P. C. (1998). Positive peer reporting to improve the social interactions of a socially rejected girl. Proven Practice: Prevention and Remediation Solutions for School Problems, 1, 17-21.

Ervin, R. A., Miller, P. M., \& Friman, P. C. (1996). Feed the hungry bee: Using positive peer reports to improve the social interactions and acceptance of a socially rejected girl in residential placement. Journal of Applied Behavior Analysis, 29, 251-253.

Field, T, (1981). Early peer relations. In P. S. Strain (Ed.), The utilization of classroom peers as behavior change agents. (pp.-30). New York: Plenum Press.

Graham, S. \& Hoehn, S. (1995). Children's understanding of aggression and withdrawal as social stigmas: An attributional analysis. Child Development, 66, $1143-1161$.

Grieger, T., Kauffman, J. A., \& Grieger, R. M. (1976). Effects of peer reporting on cooperative play and aggression of kindergarten children. Journal of School Psychology, 14, 307-313.

Harrist, A.W., Zaia, A. F., Bates, J. E., Dodge, K. A., \& Pettit, G. S. (1997). Subtypes of withdrawal in early childhood: Sociometric status and socialcognitive differences across four years. Child Development, 68, 278-294.

Hartmann, D. P. (1977). Considerations in the choice of interobserver reliability estimates. Journal of Applied Behavior Analysis, 10, 103-116. 
Hymel, S., Bowker, A., \& Woody, E. (1993). Aggressive versus withdrawn unpopular children: Variations in peer and self-perceptions in multiple domains. Child Development, 64, 879-896.

Hymel, S., Rubin, K. H., Rowden, L., \& LeMare, L. (1990). Children's peer relationships: Longitudinal prediction of internalizing and externalizing problems from middle to late childhood. Child Development, 61, 2001-2021.

Jones, K. M., Young, M. M., \& Friman, P. C. (2000). Increasing peer praise of socially rejected delinquent youth: Effects on cooperation and acceptance. School Psychology Quarterly, 15, 30-39.

Kazdin, A. M. (Ed.).(1994). Behavior modification in applied settings (5th ed.). Brooks/Cole: California.

Lewis, T. L., \& Suagi, G. (1993). Teaching communicative alternatives to socially withdrawn behavior: An investigation in maintaining treatment effects. Journal of Behavior Education, 3, 61-76.

McDermott, P. A. (1994). National profile in youth psychopathology: Adjustment scales for children adolescents. Philadelphia, PA: Edumetrio and Clinical Science.

McDermott, P. A., Marston, N. C., Stott, D. H. (1993). Adjustment scales for children and adolescents. Philadelphia, PA: Edumetrio and Clinical Science. 
Northup, J., Broussard, C., Jones, K. , George, T., Vollmer, T. R., \& Herring, M. (1995).The differential effects of teacher and peer attention for three children with a diagnosis of attention deficit hyperactivity disorder. Applied Behavior Analysis, 28, 227-228.

Northup, J., Jones, K., Broussard, C., DiGiovanni, G., Herring, M.., Fusilier, I., \& Hanchey, A. (1997). A preliminary analysis of interactive effects between common classroom contingencies and methylphenidate. Journal of Applied Behavior Analysis, 30, 121-121.

Oden, S. (1980). A child's social isolation: Origins, prevention, intervention. In G. Carteledge \& J. F. Milburn (Eds.). Teaching Social Skills to Children, pp. 179-202. New York: Pergamon Press.

Odom, S. L., \& Strain, P. S. (1984). Peer-mediated approaches to increasing children's social interactions: A review. American Journal of Orthopsychiatry, 54, 544-557.

Parker, J. G., \& Asher, S. (1987). Peer relations and later personal adjustment: Are low-accepted children at risk? Psychology Bulletin, 102, 357389.

Patterson, G. R. \& Anderson, D. (1964). Peers as social reinforcers. Child Development, 35, 951-960.

Rubin, K. H., \& Mills, R. S. L. (1988). The many faces of social isolation in childhood. Journal of Consulting and Clinical Psychology, 56, 916-924. 
Sandler, A. G., Arnold, L. B., Gable, R. A., \& Strain, P. S. (1987). Effects of peer pressure on disruptive behaviorally disordered classmates. Behavior Disorders, 12, 104-110.

Sancilio, F. M. (1987). Peer interaction as a method of therapeutic intervention with children. Clinical Psychology Review, 7, 475-500.

Sheridan, S. M., Kratochwill, T. M., \& Elliott, S. N. (1990). Behavioral consultation with parents and teachers: Delivering treatment for socially withdrawn children at home and school. School Psychology Review, 19, 33-52.

Solomon, R. W. \& Wahler, R. G. (1973). Peer reinforcement control of classroom problem behavior. Journal of Applied Behavior Analysis, 6, 49-56.

Strain, P. S. (1982). Peer-mediated treatment of exceptional children's social withdrawal. In P. S. Strain (Ed.). Social development of exceptional children (pp. 93-105). Rockville, MD: Aspen Systems Corp.

Strain, P.S. (Ed.). (1981). The utilization of classroom peers as behavior change agents. New York: Plenum.

Walker, H. M., Street, A., Garrett, B., Crossen, J., Hops, H., \& Greenwood, C. R. (1978). RECESS: Reprogramming environmental contingencies for effective social skills. Center at Oregon for Research in Behavioral Education of the Handicapped. 
Walker, H. M., Todis, B., Block, A., \& Severson, H. (1988). Standardized screening and identification of behavior disordered pupils in the elementary age range: Peer social behavior observer trainer manual. Eugene, OR: University of Oregon, Center on Human Development.

Wickstrom, K. F., Jones, K. M., Lafleur, L. H., \& Witt, J. C. (1996). An analysis of treatment integrity in school-based behavioral consultation. $\underline{\text { School }}$ Psychology Quarterly, 11, 141-154.

Younger, A. J., Schwartzman, A. E. \& Ledingham, J. E. (1986). Agerelated differences in children's perceptions of social deviance: Changes in behavior or in perspective? Developmental Psychology, 22, 531-542. 
Appendix A

\section{Parental Consent}




\author{
Eastern Illinois University * School Psychology Program \\ Department of Psychology Charleston, IL 61920
}

\title{
Parental Consent Form
}

Purpose: The purpose of this program is to provide supportive services to children with social difficulties. Children who participate will receive praise from their peers for appropriate interactions during the selected school activities. Potential benefits are that these children may feel more comfortable in these situations and learn to interact with their peers in a more acceptable manner.

Procedures: In order to assess the social status of each child, the entire class will be asked to privately and anonymously nominate the five children they would most like to interact with. The classroom instructor will then teach all children the proper steps in praising and acknowledging appropriate social skills. Observations during selected class time and other social settings will be conducted in order to determine whether this strategy is effective in increasing social behaviors. The program will be completed in approximately 4-5 weeks.

Right to Privacy: The results may be presented for training and research purposes. Therefore, all materials will receive a random code and there will be no way to link your child's name or the name of the school to any of our records. You may, however, request a copy of all materials and results of the program.

Participant's Rights: Your agreement to allow your child to participate in this project is voluntary. You have the right to withdraw at any time. If you have any questions or concerns, or would like more information about our research and training program, please contact the university trainer, Kevin Jones, Ph.D., at 217-581-2128.

I HAVE READ AND UNDERSTAND THE PURPOSE OF THE PROJECT, THE PROCEDURES INVOLVED, AND MY RIGHTS AS THE LEGAL GUARDIAN OF MY CHILD. I AGREE TO ALLOW MY CHILD TO PARTICIPATE IN THIS PROJECT.

CHILD' S NAME

Signature of Parent
Date

\section{Case \#}




\section{Appendix B}

Social Withdrawal Observation Form 
thene of studert

ate Met. Y || Sessian Cote.

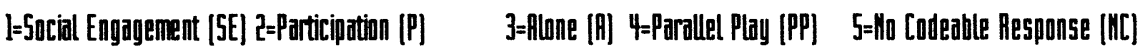

\begin{tabular}{|c|c|c|c|c|c|c|c|}
\hline 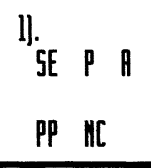 & 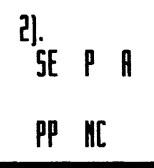 & $\begin{array}{lll}\text { 3). } & & \\
\text { SE } & P & A \\
\text { PP } & \text { IIC }\end{array}$ & $\begin{array}{l}\text { 4]. } \\
\text { SE } \\
\text { P }\end{array}$ & $\begin{array}{c}\text { 5]. } \\
\text { SE } \\
\text { PP }\end{array}$ & $\begin{array}{l}\text { 6). } \\
\text { SE }\end{array}$ & $\begin{array}{l}\text { 7]. } \\
\text { SE } P \text { A } \\
\text { PP } \mathbb{N C}\end{array}$ & $\begin{array}{lll}\text { 8). } & & \\
\text { SE } & P & \text { A } \\
\text { PP } & N C\end{array}$ \\
\hline $\begin{array}{l}\text { ID]. } \\
\text { 5E P A } \\
\text { PP NIC }\end{array}$ & $\begin{array}{l}\text { 11]. } \\
\text { SE P A } \\
\text { PP NC }\end{array}$ & 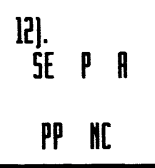 & $\begin{array}{l}\text { [3]. } \\
\text { 5E P } \\
\text { PP NC }\end{array}$ & $\begin{array}{l}\text { 14]. } \\
\text { SE P A } \\
\text { PP NIC }\end{array}$ & $\begin{array}{l}\text { [5]. } \\
\text { SE P } \\
\text { PP NC }\end{array}$ & $\begin{array}{l}\text { l6]. } \\
\text { SE P A } \\
\text { PP NC }\end{array}$ & $\begin{array}{lll}\text { 17]. } & & \\
\text { SE } & P & \text { A } \\
\text { PP } & N[\end{array}$ \\
\hline $\begin{array}{l}\text { 19]. } \\
\text { SE } \\
\text { Pp }\end{array}$ & $\begin{array}{l}\text { 20]. } \\
\text { SE P } \\
\text { PP } \mathbb{A C}\end{array}$ & $\begin{array}{l}\text { [l]. } \\
\text { SE P A } \\
\text { PP NI }\end{array}$ & $\begin{array}{c}\text { [2]]. } \\
\text { SE } \\
\text { PP } \quad \text { A }\end{array}$ & $\begin{array}{l}\text { [3]. } \\
\text { SE P } \\
\text { PP } \mathbb{N}\end{array}$ & $\begin{array}{l}\text { ㄴ] } \\
\text { SE P A } \\
\text { PP NIC }\end{array}$ & $\begin{array}{l}\text { 25]. } \\
\text { SE P A } \\
\text { PP NC }\end{array}$ & $\begin{array}{l}\text { 26]. } \\
\text { SE P A } \\
\text { PP NC }\end{array}$ \\
\hline $\begin{array}{l}\text { 28]. } \\
\text { SE } \\
\text { PP }\end{array}$ & $\begin{array}{l}\text { [g]. } \\
\text { SE } \\
\text { PP }\end{array}$ & $\begin{array}{l}\text { 30]. } \\
\text { SE P } \\
\text { PP }\end{array}$ & $\begin{array}{l}\text { 3!]. } \\
\text { SE } \\
\text { PP }\end{array}$ & $\begin{array}{l}\text { J2]. } \\
\text { SE } \\
\text { PP }\end{array}$ & $\begin{array}{l}\text { 33]. } \\
\text { SE } \quad \text { P } \\
\text { PP } N[\end{array}$ & $\begin{array}{l}\text { 34]. } \\
\text { SE P } \\
\text { PP N N }\end{array}$ & $\begin{array}{l}\text { 35]. } \\
\text { SE } \mathbb{A} \text { A } \\
\text { PP NC }\end{array}$ \\
\hline $\begin{array}{l}\text { 37]. } \\
\text { SE P A } \\
\text { PP } \|[\end{array}$ & $\begin{array}{c}\text { 38]. } \\
\text { SE P A } \\
\text { PP NC }\end{array}$ & 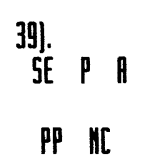 & $\begin{array}{l}\text { 40]. } \\
\text { SE P A } \\
\text { PP NIC }\end{array}$ & $\begin{array}{l}\text { 41]. } \\
\text { SE P A } \\
\text { PP NC }\end{array}$ & $\begin{array}{l}\text { 42]. } \\
\text { SE P A } \\
\text { PP NC }\end{array}$ & $\begin{array}{l}\text { 43]. } \\
\text { SE P A } \\
\text { PP NC }\end{array}$ & $\begin{array}{l}\text { 44]. } \\
\text { SE P A } \\
\text { PP NC }\end{array}$ \\
\hline $\begin{array}{l}\text { 46]. } \\
\text { 5E P A } \\
\text { PP NC }\end{array}$ & $\begin{array}{l}\text { 47]. } \\
\text { SE P A } \\
\text { PP NIC }\end{array}$ & $\begin{array}{l}\text { 48]. } \\
\text { SE P A } \\
\text { PP NC }\end{array}$ & $\begin{array}{l}\text { 49]. } \\
\text { 5E P } \\
\text { PP NIC }\end{array}$ & $\begin{array}{l}\text { 50]. } \\
\text { 5E P A } \\
\text { PP NIC }\end{array}$ & $\begin{array}{l}\text { 51]. } \\
\text { SE P A } \\
\text { PP NC }\end{array}$ & $\begin{array}{l}\text { 52]. } \\
\text { SE } P \text { A } \\
\text { PP NIC }\end{array}$ & $\begin{array}{l}\text { 53]. } \\
\text { SE } \\
\text { P A } \\
\text { PP NC }\end{array}$ \\
\hline $\begin{array}{l}\text { 55]. } \\
\text { SE P A } \\
\text { PP NC }\end{array}$ & $\begin{array}{l}\text { 56]. } \\
\text { 5E P A } \\
\text { PP NC }\end{array}$ & $\begin{array}{l}\text { 57!. } \\
\text { SE P A } \\
\text { PP NC }\end{array}$ & $\begin{array}{l}\text { 58]. } \\
\text { 5E P A } \\
\text { PP NC }\end{array}$ & $\begin{array}{l}\text { 59]. } \\
\text { 5E P A } \\
\text { PP NC }\end{array}$ & $\begin{array}{l}\text { 60]. } \\
\text { 5E P } \\
\text { PP NC }\end{array}$ & $\begin{array}{l}\text { bll. } \\
\text { SE } P\end{array}$ & $\begin{array}{l}\text { 62]. } \\
\text { SE } P \text { 月 } \\
\text { PP } \mathbb{N C}\end{array}$ \\
\hline $\begin{array}{l}\text { 64]. } \\
\text { SE P A } \\
\text { PP NIC }\end{array}$ & $\begin{array}{l}\text { 65). } \\
\text { 5E P A } \\
\text { PP NC }\end{array}$ & $\begin{array}{l}\text { 6f]. } \\
\text { SE P } \mathrm{A} \\
\text { PP NC }\end{array}$ & $\begin{array}{l}\text { 57]. } \\
\text { SE P A } \\
\text { PP NC }\end{array}$ & $\begin{array}{l}\text { 6B]. } \\
\text { SE P A } \\
\text { PP NC }\end{array}$ & $\begin{array}{l}\text { 69]. } \\
\text { SE P A } \\
\text { PP NC }\end{array}$ & $\begin{array}{l}\text { 70]. } \\
\text { SE P A } \\
\text { PP NIC }\end{array}$ & $\begin{array}{l}\text { 71]. } \\
\text { SE } P \text { 月 } \\
\text { PP } \| C\end{array}$ \\
\hline $\begin{array}{l}\text { 73]. } \\
\text { SE P A } \\
\text { PP NIC }\end{array}$ & $\begin{array}{l}\text { 74]. } \\
\text { SE P A } \\
\text { PP NIC }\end{array}$ & $\begin{array}{c}\text { 75]. } \\
\text { SE P A } \\
\text { PP IIC }\end{array}$ & $\begin{array}{l}\text { 75]. } \\
\text { SE P A } \\
\text { PP NC }\end{array}$ & $\begin{array}{l}\text { T7]. } \\
\text { SE P A } \\
\text { PP } \|[\end{array}$ & $\begin{array}{l}\text { 78]. } \\
\text { SE P A } \\
\text { PP NIC }\end{array}$ & $\begin{array}{c}\text { 79]. } \\
\text { SE P } \\
\text { PP } \mathbb{~ N C ~}\end{array}$ & $\begin{array}{l}\text { BD]. } \\
\text { SE P A } \\
\text { PP NC }\end{array}$ \\
\hline
\end{tabular}

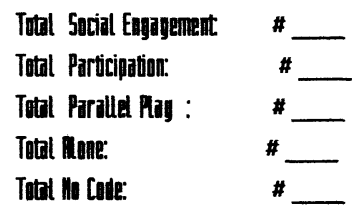

Total Social Engagenent =

Total Participation: $\quad=-4 / 6$

Totol Paralled Par:

Totat Whane:

Total in Cate 
Peer Reporting 50

Appendix C

Behavioral Categories 


\section{Behavioral Categories}

Adopted from the Systematic Screening for Behavioral Disorders Scale: Peer Social Behavior Observation Training Manual ( Walker, Todis, Block, \& Severson, 1988)

1). Social Engagement: The child is interacting with peer (s) verbally or nonverbally in a polite manner, such as talking, holding hands while walking, or playing on a piece of playground equipment.

2). Participation: The child is involved in a game with equipment.

3). Alone: The child is not within five feet of peer (s) or adults.

4). Parallel Play: The child is engaged in similar activity as peer (s) within five feet, but is not directly interacting (verbally, or nonverbally), such as swinging next to a peer but not initiating or responding to social interaction cues such as talking, smiles, or eye contact.

5). No Codeable Response: The child is interacting with adults, out of sight of observer, or engaging in behavior that does not fit into one of the categories. 
Peer Reporting 52

Appendix D

Sociometric Rating Scale 
DIRECTIONS: Write down the names of five classmates who you most often play with.

1).

2).

3).

4).

$5)$. 
Appendix E

\section{Teacher Checklist}


Teacher Checklist for the Positive Peer Reporting Procedure

Directions: Please check off each item that was completed today for the positive peer reporting procedure.

1). Told the class that the positive peer reporting procedure is about to begin.

2). Reviewed the four essential steps with the class and pointed to them listed on the poster board.

a. Look at the person.

b. Smile.

c. Describe something the star said or did.

d. Praise the star.

3). Praised each student for an appropriate comment

4). How many students did not participate (e.g. refused, or just couldn't think of anything, or said something that wasn't considered positive). 
Peer Reporting 56

Figure Caption

Figure 1 displays the percentage of social involvement for each participant across baseline and treatment phases. 


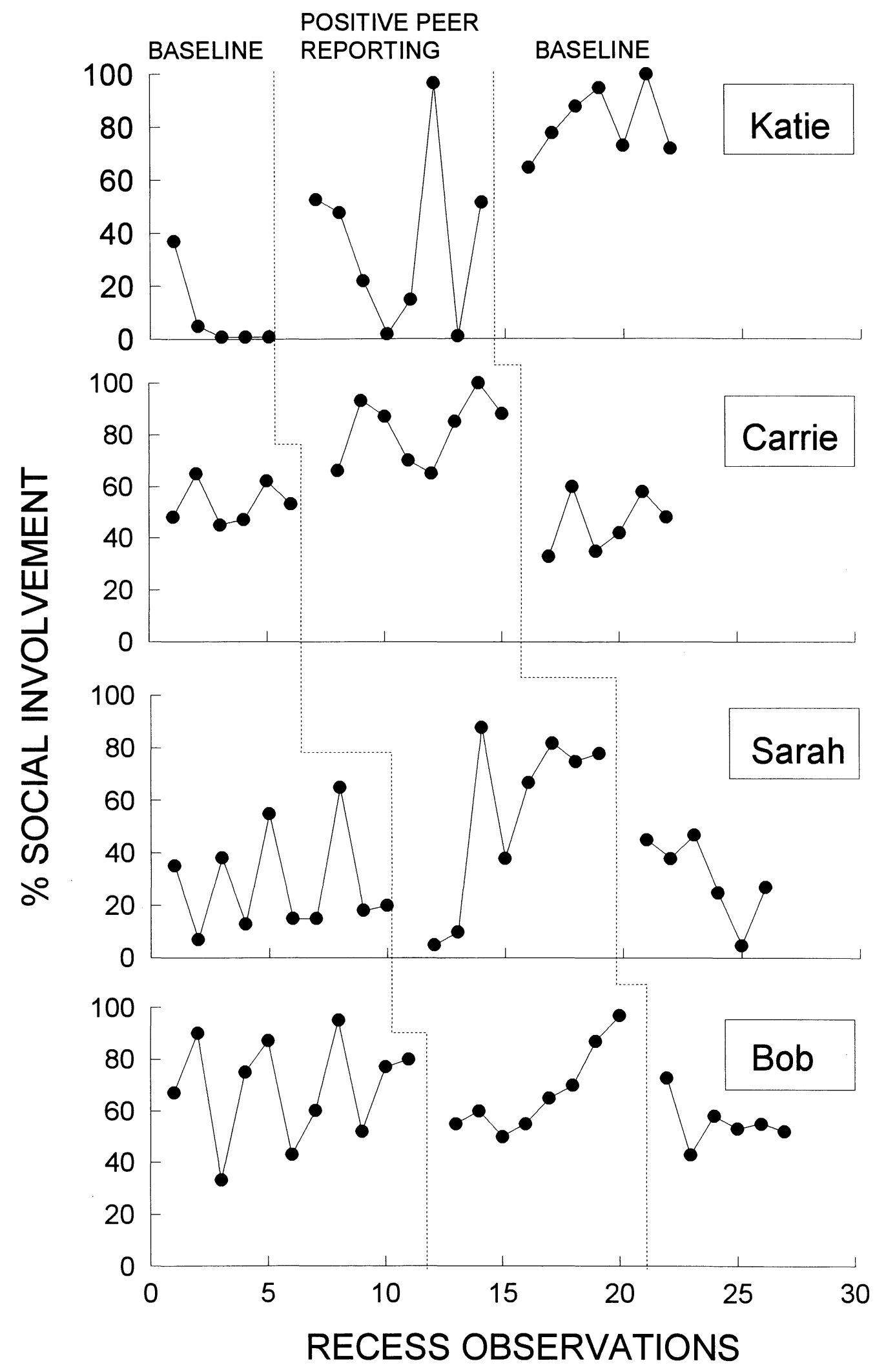

